\title{
Investigation into Road Construction Safety Management Techniques
}

\author{
David Nkurunziza \\ Department of Civil, Environment and Geomatics Engineering, School of Engineering, College of Science and Technology, \\ University of Rwanda, Kigali, Rwanda \\ Email: david.nziza@gmail.com
}

How to cite this paper: Nkurunziza, D. (2020) Investigation into Road Construction Safety Management Techniques. Open Journal of Safety Science and Technology, 10, 81-90.

https://doi.org/10.4236/ojsst.2020.103007

Received: May 21, 2020

Accepted: August 31, 2020

Published: September 3, 2020

Copyright $\odot 2020$ by author(s) and Scientific Research Publishing Inc. This work is licensed under the Creative Commons Attribution International License (CC BY 4.0).

http://creativecommons.org/licenses/by/4.0/

(c) (i) Open Access

\begin{abstract}
Rwanda is undergoing rapid development in transportation through constructing new roads and upgrading existing ones. During implementation of these projects, many accidents for road workers, road users and environment issues are raised due to unsafe road construction management techniques. This existing problem was carried out within the City of Kigali for three ongoing road construction projects namely road Ruliba-Karama-Nyamirambo, Kigali Urban Road Upgrading Projects of Agatare and the Sonatube-GahangaAkagera road, in order to investigate about the road construction safety management techniques. From the findings, $64.28 \%$ results showed that the maintaining of health and safety policy in the road construction sites is applied and there exist different means of maintaining safety, such as the provision of PPE (Personal Protective Equipment) to the workers at the level of $57.14 \%$ as per the project managers; but from the field observations, it is alarming, and many workers do not wear as required. It was also found that $50 \%$ of accidents occurring in excavation works among all work performed during road construction are due to lack of adequate safety measures. The paper indicated that $85.71 \%$ of the concerned workers do conduct training and induction in their road safety construction sites, but on the other hand the level of accidents due to lack of safety recorded in the road construction sites is still high at the level of $78.57 \%$. The mostly affected are unskilled laborers and this observation begs the question about the training and induction of workers in road safety and its effectiveness of on the concerned workers. The paper suggests some different safety measures to apply for providing safe road working environment according to the standard and gives some key recommendations for Rwanda.
\end{abstract}

\section{Keywords}

Accident, Road Safety, Road Construction Projects, Safety Management 


\section{Introduction}

The importance of providing safe workplace has been reiterated by various related studies because of the intrinsic hazard and risk factors that undoubtedly underlie every work situation and their negative impact on a company's overall performance [1].

The safety of road-workers is a high priority for occupational health and road safety authorities and, especially, for the workers themselves and the organizations which employ and represent them. There are substantial risks involved in undertaking road construction in close proximity to moving traffic, and compromises between traffic flow, acceptable risk exposure levels, and equipment and resource levels associated with such tasks [2].

Construction safety involves defined safety procedure that is related to the construction industry or construction sites and aims to ensure that a construction site or the industry as a whole is not the cause of immediate danger to the public around a construction site, or the workers at a construction site, as well as making sure that the finished product of construction meets required safety standards.

In Rwanda, specifically in the City of Kigali, there is a need of improving transportation routes through constructing and upgrading roads. During road construction, safety management is needed in order to reduce injuries and fatalities on construction sites, but in some road construction projects, safety is not being used as it has been highlighted in Figure 1 and Figure 2.

That is why an investigation to safety management techniques was conducted in order to have a better understanding to the prevailing situation on some selected works for Nyarugenge sector (Agatare) infrastructure upgrading, road construction of Ruliba-Karama-Nyamirambo and Road construction of Sonatube-Gahanga-Akagera in the City of Kigali.

\section{Materials and Method}

One of the most crucial factors in road construction site is the safety of road users and the construction workers as well as working environment. This paper main objective was to investigate the safety management techniques, issues, problems and compared to the standard ones as per the Indian Standard [3] and specifically assess the existing safety measures being used in Rwandan road construction industry, look at the reason behind the negligence of safety measures in some road construction projects and highlight the benefits of achieving safety measures to the public.

\subsection{Description of the Study Area for Roads}

The study was conducted on three ongoing road construction projects within the City of Kigali by that time named Ruliba-Karama-Nyamirambo $(6.9 \mathrm{~km})$; Agatare Road of Kigali urban roads upgrading projects $(5 \mathrm{~km})$ and SonatubeGahanga-Akagera road of $(13.8 \mathrm{~km})$. 


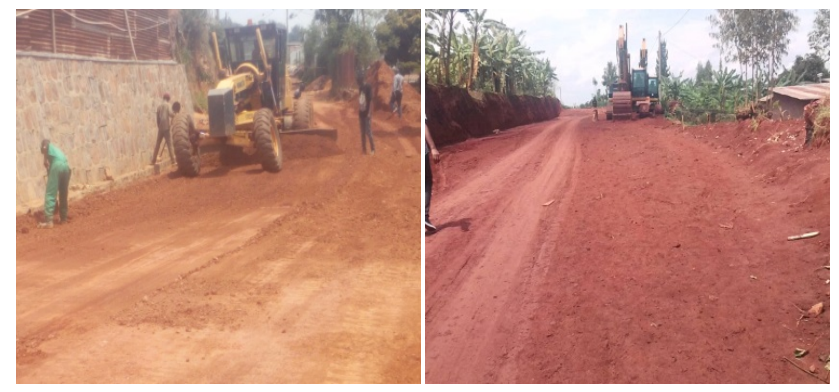

Figure 1. Lack of safety measures for site workers with construction equipment.
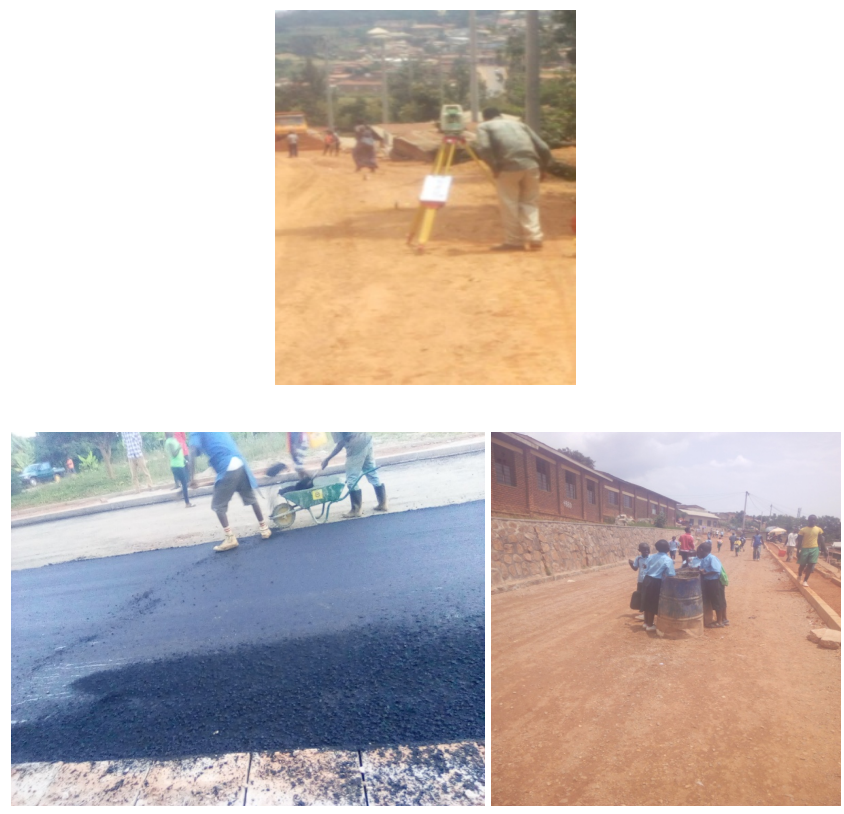

Figure 2. Lack of safety measures to road Workers for asphalt and land surveying activities and road users like children.

\subsection{Research Design, Population and Sampling}

The study was a descriptive survey as the method of gathering information by administering a questionnaire for selected samples [4]. The descriptive survey study was used because it was best favorable to answer the "why" and "what" research questions in the study.

A stratified sampling method was used to dispatch hundreds of copies for assessing how the workers and users are dealing with the road construction environment. In addition to that from field observation the following information were noted down including the use of Personal protective equipment (PPE), use and availability of road temporary signs during construction works.

\subsection{Data Collection Techniques and Analysis Procedure}

Data collected from questionnaires were analyzed both qualitatively and quantitatively and data from field observations were noted down systematically. After field work, some of the data collected were edited, matched to the questions and organized basing on responses. 


\section{Findings}

\subsection{Primary Data Population Size and Class}

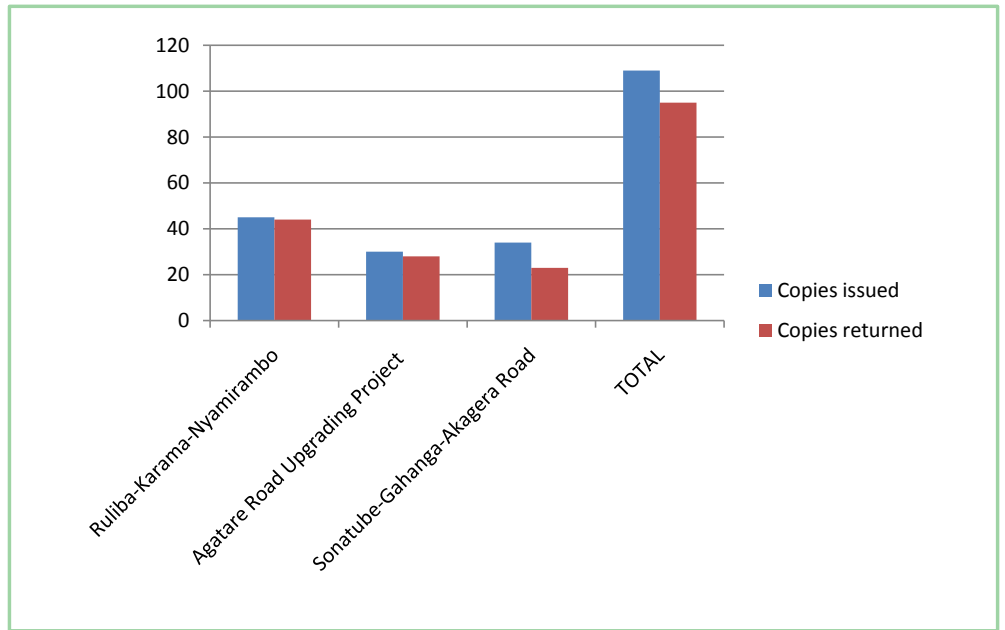

Figure 3. Population structure.

\subsection{Health and Safety Management Systems}

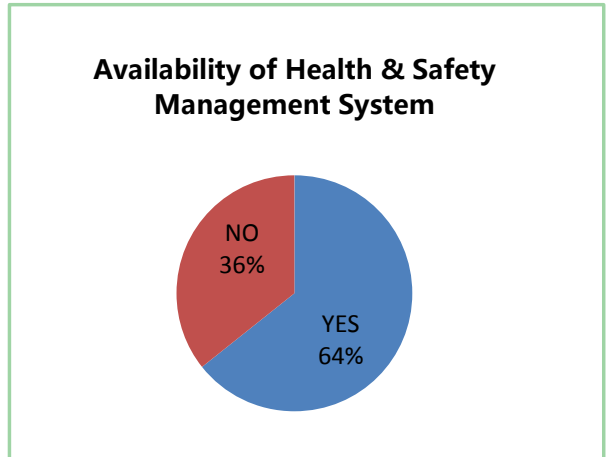

Figure 4. Availability of health and safety management system.

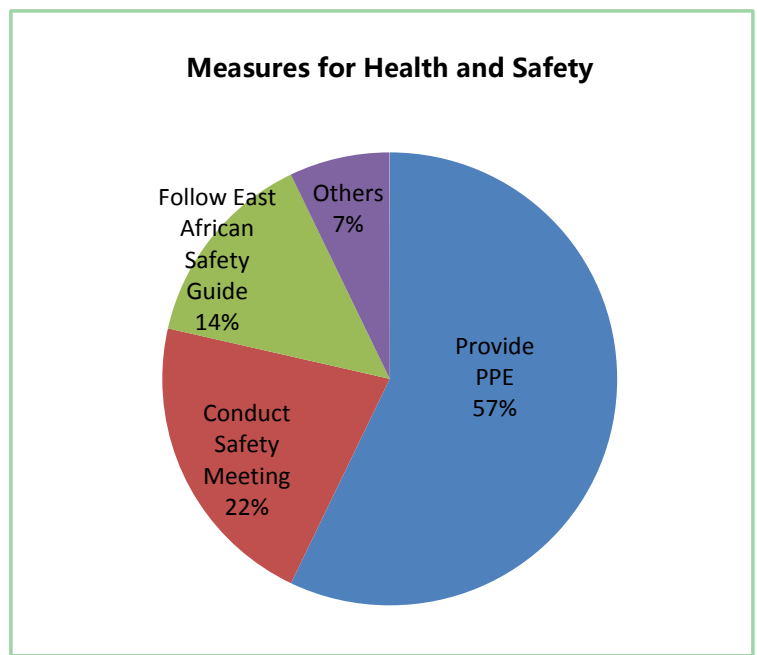

Figure 5. Proposed measures to deal with health \& safety management. 
3.3. Accidents Occurrence and Nature Recorded on the Site
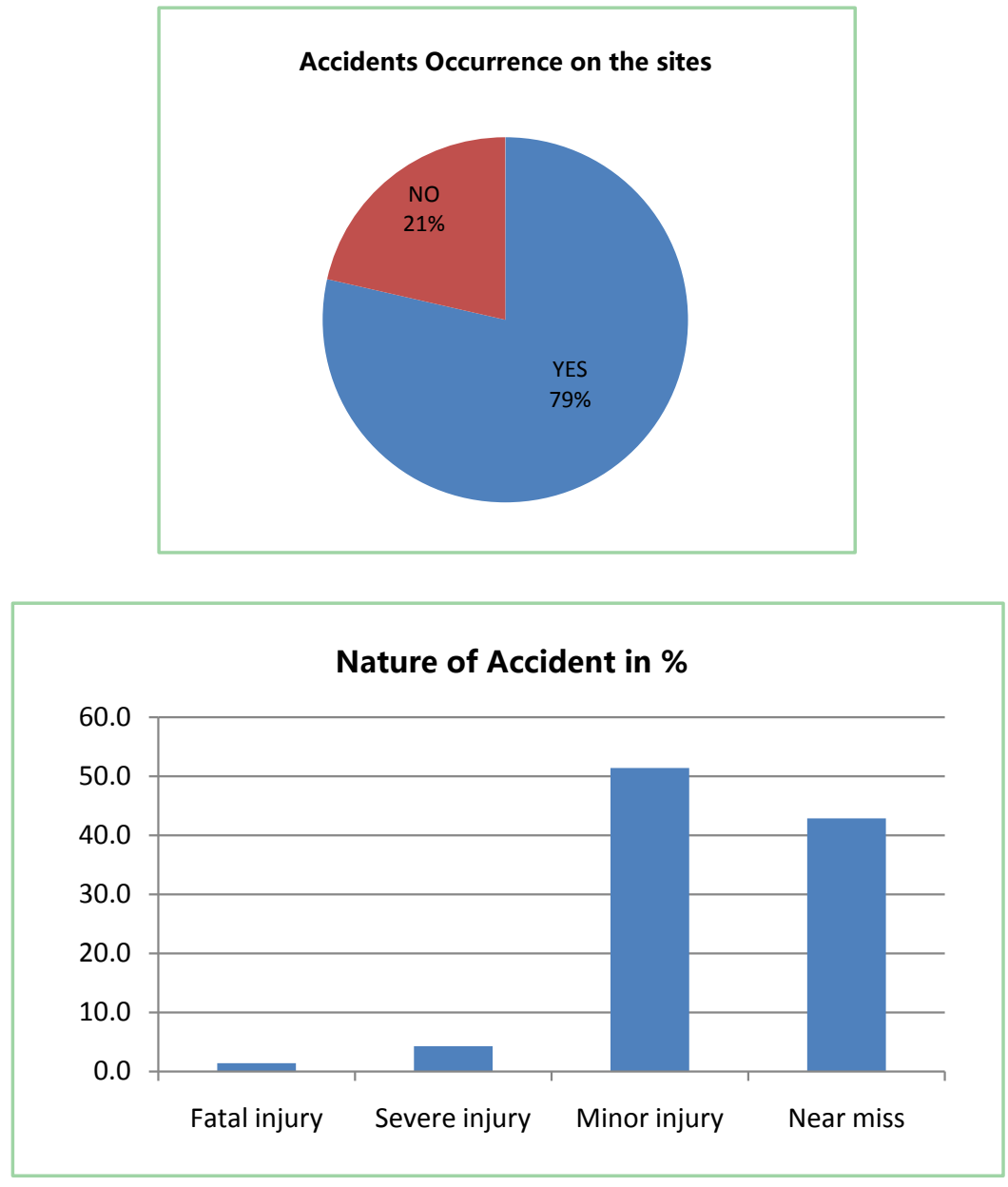

Figure 6. Occurrence and nature of site accidents.

\subsection{Work Category for the Accident Victims}

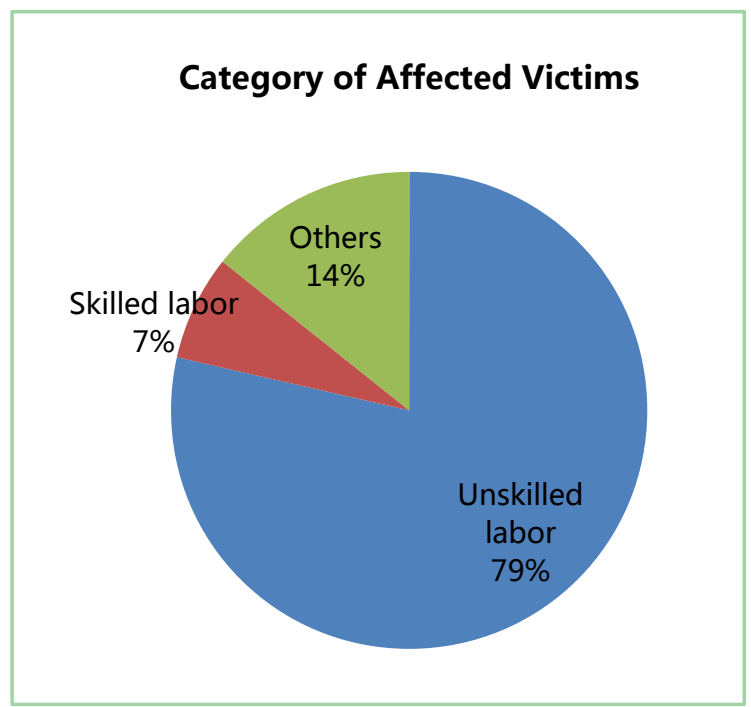

Figure 7. Number of affected victims by category. 


\subsection{Causes of the Site Accidents and Where Most Likely to Occur}
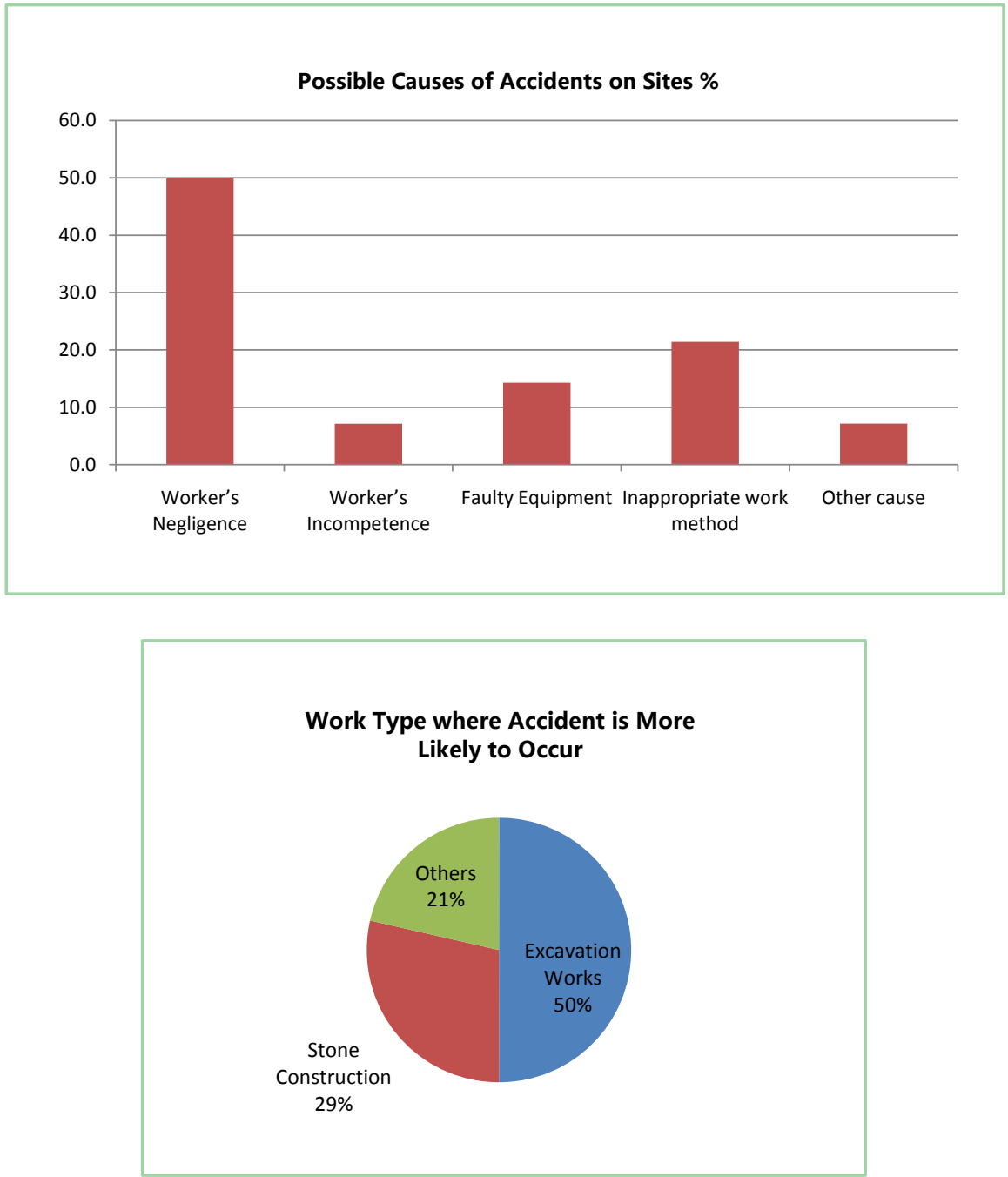

Figure 8. Work type at which accident occurs.

\subsection{Training and Induction Information}

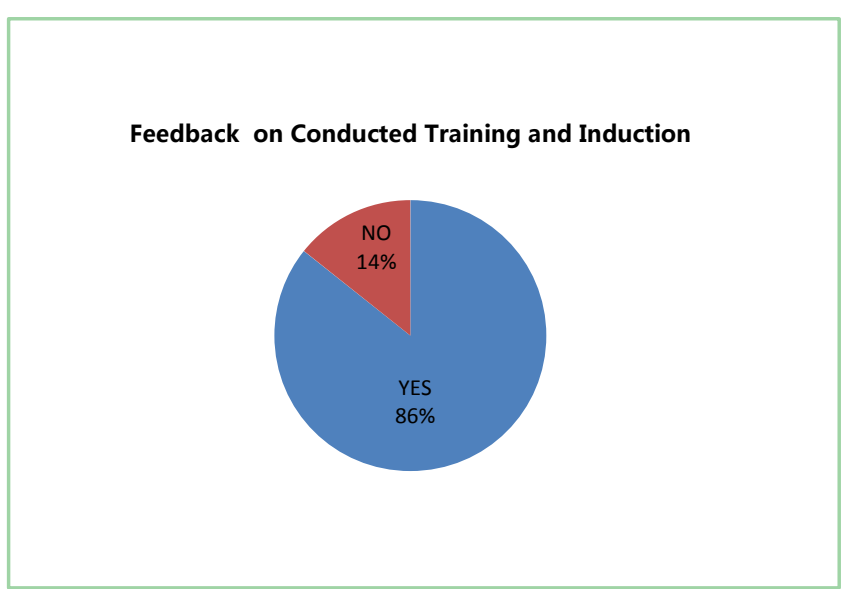

Figure 9. Feedback on training and induction matter. 


\subsection{Field Findings}
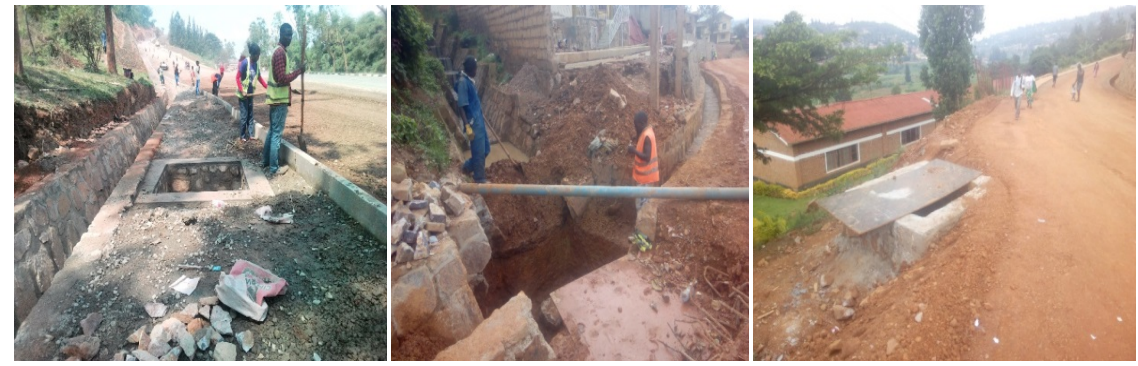

Figure 10. Lack of protective information for Manholes at Karama, Akagera and Agatare roads respectively.

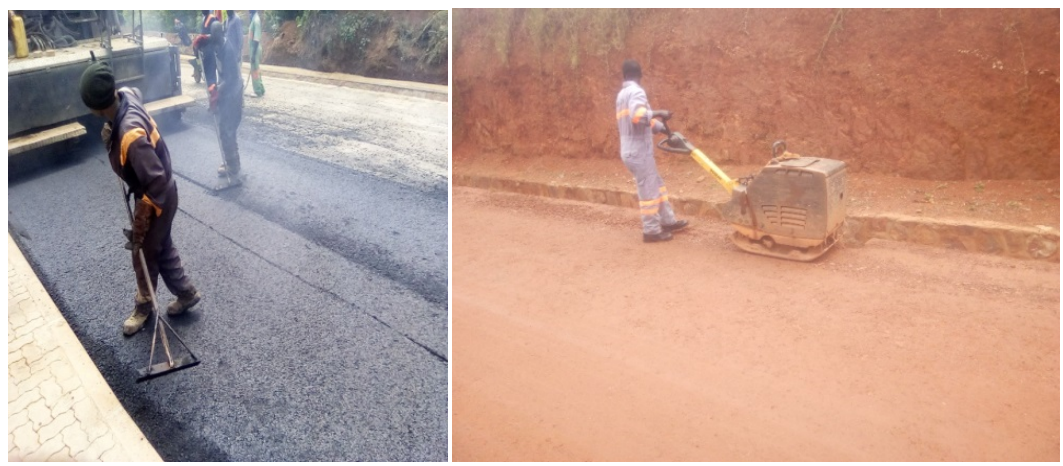

Figure 11. Lack of Protective equipment's like masks, helmet and gloves at Karama and Akagera Roads respectively during implementation on site.

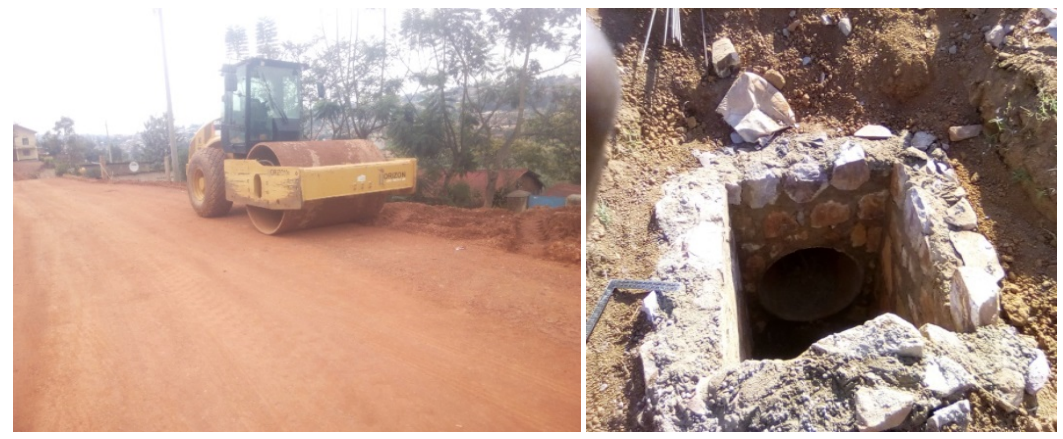

Figure 12. Lack of Adequate Signs to warn parked Machine at Karama Road and a manhole under construction at Akagera Road.

\subsection{Secondary Data Findings}

Referring to the Rwandan guidelines [5] Articles 90-96 of the Law regulating Labor in Rwanda, 2009 (known as Labor Code), Article 4, Article 7 and Article 28 of the Ministerial Order N ${ }^{\circ} 02$ Of 17/05/2012 Determining Conditions For Occupational Health And Safety); Ministerial Order No. 01/MIFOTRA/15 of 15/01/2015 Determining Modalities Of Establishing And Functioning Of Occupational Health And Safety Committees) the following were health and safety rules and regulations set to be followed during road constructions works. It was provided information about the Employer Cares, Free Protection and Training. 


\section{Discussion}

As per the findings $64.28 \%$ of the results showed that that concerned construction companies maintain health and safety policy in their road construction sites and stated that different means of maintaining safety, are provided at the level of $57.14 \%$ to the workers. Figure 3 stated about the Population Structure about data collection on three selected sites.

Figure 4 gives a pictorial understanding about the health and safety management systems found on visited construction sites and the health and safety system is at the level of $64 \%$ described as interesting. Figure 5 proposes some measures that could be implemented in order to deal with health and safety management effectively on construction sites as per the respondent views. Figured 6 describes the nature of accidents that are more likely on site like minor injury and their degree of occurrence. Figure 7 informs us about the categories of workers that are affected on site due to the lack of health and safety measures and many fall under unskilled labor category of people. Figure 8 outlines possible causes of accidents that are mainly negligence that causes more accidents occurring during excavation works. Figure 9 informs about if the training and induction to workers for site activities is conducted. As per the Indian standards IS 13430:1992, reviewed in 2007, works for trenches and foundation pits in road construction shall be adequately and securely fenced in order to protect the surrounding features such as buildings, workers, road users and environment, provided with proper caution signs and marked with red lights at suitable intervals during night to avoid accidents. Unfortunately this is not the case as shown in Figure 10 from the field observations. In addition to that, the secondary data suggest that during compaction operator must have a hard hat (helmet), ear plugs, work gloves and steel - toed safety boots and as shown in Figure 11 an operator has only the safety boots but from the field observations is quite different.

Figure 12 illustrates the field situation of the lack of adequate signs to warn about parked machines and equipment on road construction site and exposes the danger about non-covered and protected manholes.

The safety measures of the road construction projects were found to be very weak due to the fact that most of $50 \%$ of accidents occur in excavation works among all work performed during road construction due to negligence.

Concerning the impact of training and inductions in carrying out safety measures in road construction sites, this would involve the provision of information and instruction about work, health and management plans on a construction site, so as to ensure that people engaged to undertake construction work have a basic knowledge of the preventive measures needed to address possible hazards identified in a particular task.

It is clearly observed that the training is possibly not adequate and may be very short because the findings indicate that $85.71 \%$ of workers seem to have conducted training and induction in their road construction sites but on the 
other hand the level of accidents recorded in the road construction sites by the respondents is still high at the level of $78.57 \%$. Although most of the recorded accidents are minor in nature $51.42 \%$ and mostly affected unskilled laborers (78.57\%) this observation begs the question about the category of workers included in the training and induction programs in road construction sites and the effectiveness of such training and induction.

\section{Conclusions}

It is clear that Rwanda has guidelines to be followed during road construction but by comparing with Indian Standard (IS) terms there are some missing important points about trenches and foundation pits works, deep excavation works and parking of movable equipment's safety measures.

The worker's negligence is on high level of $50 \%$ of other causes of accident, the paper figured out the reason behind negligence of safety rules and found that the major reason is the unfamiliar safety guidelines and lack of regular training and safety meetings. The safety management techniques are important in road construction as they help in development of nation, speed up the project implementation through health workers and safe working environment, reduction of accidents and delay for road users during construction through effective communication, protective, informative and warning signs.

The paper came up with the following recommendations:

- The establishment of a workplace health and safety committee would be suggested on road construction site;

- A construction site should be having a copy of safety rules and guidelines at work and the Safety guidelines must be provided separately depending on type of work not in general;

- The paper also recommended to follow the following guidelines as per IS 13430:1992, reviewed in 2007 which are not included in Rwanda's guidelines but are exclusively important to follow and include caution signs and marked with red lights at suitable intervals, notice boards and danger signals should be provided; danger lights during darkness hours, Barriers or coverings should be provided to excavations, distance where to park unused equipments;

Finally, there is a need of updating and establishing the new Rwanda's guidelines on safety management techniques for road construction sites specifically in urban and rural areas.

\section{Conflicts of Interest}

The author declares no conflicts of interest regarding the publication of this paper.

\section{References}

[1] Olutuase, S.O. (2014) A Study of Safety Management in the Nigerian Construction 
Industry. IOSR Journal of Business and Management, 16, 1-10.

https://pdfs.semanticscholar.org/c8d2/a99a53195f9ea3b3c901cbb7dd5bcd3aa7b0.pd $\mathrm{f}$

[2] Debnath, A.K., Banks, T., Blackman, R., Dovan, N., Haworth, N. and Biggs, H. (2014) Beyond the Barriers: Road Construction Safety Issues from the Office and the Roadside. In: Ahram, T., Karwowski, W. and Marek, T., Eds., Proceedings of the 5 th International Conference on Applied Human Factors and Ergonomics, AHFE 2014, Kraków, 19-23 July 2014, 185-192.

[3] Bhawn, M. and Marg, B.S.Z. (1992) Code of Practice for Safety during Additional Construction and Alteration to Existing Buildings: Construction Management Including Safety in Construction IS 13430: 1992. Civil Engineering Department, Bureau of Indian Standards, New Delhi 11002.

[4] Orodho, A.J. (2003) Essentials of Educational and Social Science Research Methods. Mazola Publishers, Nairobi.

[5] Republic of Rwanda (2009) Law No. 13/2009 of 27/05/2009 Regulating Labor in Rwanda. http://www.ilo.org/dyn/natlex/natlex4.detail?p_lang=en\&p_isn=81725 